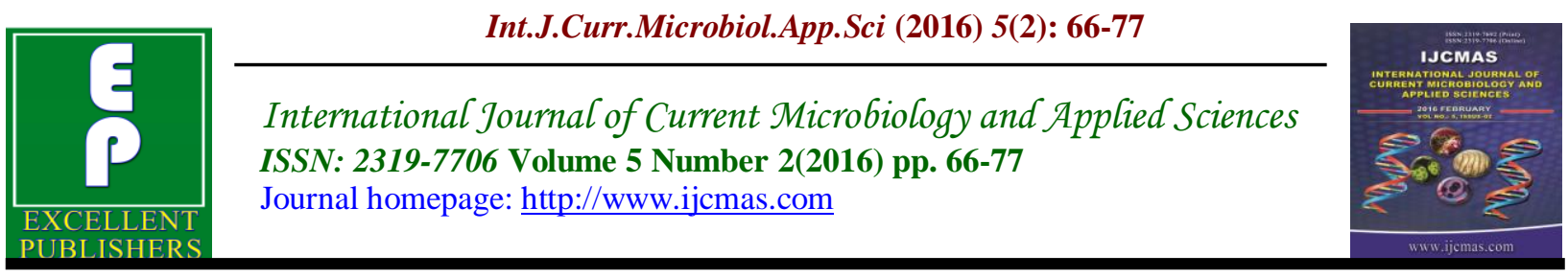

Original Research Article

doi: http://dx.doi.org/10.20546/ijcmas.2016.502.007

\title{
Identification and Antibiogram of Various Gram Positive Bacterial Isolates from Pyogenic Samples by VITEK® 2 Compact System
}

\author{
Shivani Khullar*, Laxmi Rathore, P. K. Khatri, R. S. Parihar, Saroj Meena, \\ Archana Bora, Vinod Maurya and Niranjan Sharma \\ Department of Microbiology, Dr. S. N. Medical College, Jodhpur, Rajasthan, India \\ *Corresponding author
}

\begin{abstract}
A B S T R A C T
\section{Keywords \\ Antimicrobial susceptibility, Vitek-2, \\ Pyogenic samples, resistance, Staphylococcus, Gram positive cocci.} Antibiotic

\section{Article Info}

Accepted:

09 January 2016 Available Online: 10, February 2016

Drug resistance is a burning issue for bacterial isolates and in- appropriate use of antibiotics is one of the most important factors that could affect the increasing patterns of resistance. A predictable bacterial profile and antibiotic sensitivity will be of great help for clinicians to start empirical treatment. Hence periodical monitoring of bacterial profile and their antibiotic susceptibility pattern is important. Various clinical samples were obtained from 70 subjects from various departments of Hospitals which are associated with Dr. S. N. Medical College, Jodhpur, Western Rajasthan using aseptic methods and were processed in the laboratory immediately by using standard microbiological procedures. The bacterial isolates were identified by Gram's staining and Vitek-2 compact automated system. The AST pattern of the isolates was also obtained by Vitek-2 compact automated system. Culture positivity in males was60.00\% and $40.00 \%$ in females ( $\mathrm{M}: \mathrm{F}=3: 2)$. Analysis of samples by Vitek-2 revealed that Staphylococcus aureus (40\%) was the most common bacterial isolate followed by Enterococcus spp. (37.14\%) and CONS (Coagulase negative Staphylococcus aureus) (22.85\%). Among S. aureus16 (57.14\%) were found to be Methicillin resistant Staphylococcus aureus (MRSA). The AST pattern showed that Tigecycline (58.33\%), Nitrofurantoin (45.96\%) and Vancomycin $(40.36 \%)$ were the most susceptible drugs for the above isolates Changing antimicrobial resistance pattern poses challenge in treating pyogenic infections. It is very important to reduce frequent misuse; inadequate dosages and easy availability of antimicrobials to avoid antibiotic resistance. This study will thereby guide the clinician in choosing appropriate antibiotics which not only contributes to better treatment but their judicious use will also help in preventing emergence of resistance to the drugs which are still sensitive. Identification and AST pattern of bacterial isolates by Vitek-2 compact system is of great help to the clinicians as compared to the standard methods used, the use of Vitek-2 compact system would reduce the turnaround time by at least $16 \mathrm{hrs}$.
\end{abstract}

\section{Introduction}

Pyogenic infection is characterized by local inflammation, usually with pus formation, generally caused by one of the pyogenic bacteria, which can produce the accumulation of dead leukocytes and 
infectious agent commonly known as pus ${ }^{(1)}$. Pyogenic infections may be endogenous or exogenous ${ }^{(2)}$.

The evolution of antibiotic resistance in bacteria is a topic of major medical importance and poses an urgent medical problem worldwide ${ }^{(3)}$. Antimicrobial resistance has resulted in increased morbidity and mortality as well as prolonged hospital stay and health care costs ${ }^{(4)}$.

The emergence of antibiotic resistance is an evolutionary process that is based on selection for organism that has enhanced ability to survive dose of antibiotic that would previously be lethal (Cowntey et al., $2008)^{(5)}$.

Current antibiotics target a small set of proteins essential for bacterial survival. As a result, antibiotic resistant strains are subjected to a strong positive selection pressure $^{(6)}$. Inappropriate and excessive use of antibiotics have contributed to the emergence of pathogens that are highly resistant to most currently available antibiotics $^{(7)(8)(9)}$. The novel approach of inhibiting pathogen virulence while minimizing the selection pressure for resistance holds great promise as an alternative to traditional antibiotic treatment $^{(6)}$. Knowledge of the pattern of antibiotic resistance among isolates is very important both clinically and epidemiologically ${ }^{(10)}$.A predictable bacterial profile is of great importance for clinicians to start empirical treatment for patients, while laboratory culture reports are awaited.

Because of the increased incidence of diseases caused by the microorganisms and the emergence of resistance to several antimicrobial agents ${ }^{(11,12,13,14,15,16)}$,rapid and accurate identification as well as MIC evaluation for these pathogens has become increasingly important ${ }^{(17)}$. Rapid detection, identification, and antimicrobial susceptibility testing of bacteria are also crucial in patient management. The time required to obtain a culture result is much longer in situations of low bacteria counts or infection with slow-growing bacteria. Faster reporting of bacterial identification and susceptibility results will have both clinical and financial benefits ${ }^{(18)(19)(20)(21)(22)}$.

Hence the aim of this study is to identify Antimicrobial Susceptibility Pattern of Gram Positive Cocci from various Pyogenic samples by VITEK® 2 Compact System.

The VITEK system originated in the 1970s as an automated system for identification and AST and has evolved today into the VITEK 2 system, which automatically performs all of the steps required for identification and AST after a primary inoculum has been prepared and standardized $^{(23)}$.The optical system combines multichannel fluorimeter and photometer readings to record fluorescence, turbidity, and colorimetric signals ${ }^{(17)}$.

Advantages of the VITEK® 2 Compact System-An automated loading mechanism eliminates manual steps, therefore increasing efficiency; Reads every 15 minutes for greater speed in identification and automatically prints the results when available, if configured to do so, providing added flexibility $^{(24)}$.

\section{Materials and Methods}

The present study was conducted in Tertiary care hospitals attached to Dr. S.N.Medical College (Jodhpur) Western Rajasthan.

\section{Study Material}

A total number of 70 samples were collected for aerobic culture and sensitivity from both inpatients and outpatients of various departments of Hospitals, which are 
associated with Dr. S.N. Medical College, Jodhpur, Western Rajasthan.

\section{Laboratory Procedures}

With universal safety precautions and recommended standard methods samples were collected from patients. The samples were then transported and processed in the microbiology laboratory immediately. Various clinical samples such as pus, sputum, vaginal fluid, pericardial secretion, central line tip, urine, tracheal secretion were used. Gram staining was done and the culture specimens were inoculated onto Blood agar, MacConkey agar and Nutrient Agar media by standard techniques. The plates were incubated at $37^{\circ} \mathrm{C}$ under aerobic condition in an incubator for 24 hours and the growth was observed next day. Cultures with growth were then identified by Gram's staining as gram positive cocci.

On correlating the Gram's staining and culture report, further identification and antimicrobial susceptibility testing of bacteria grown in standard aerobic conditions in an incubator at $37^{\circ} \mathrm{C}$ was done by Vitek-2 Compact System. All Grampositive cocci were investigated and cultures with mixed growth were excluded.

\section{Identification of Bacterial species by Automated Vitek-2 System}

Pure colonies of GPC which were grown on Nutrient Agar and Blood Agar were used for identification in VITEK 2. The method of identifying species is-

Step 1: Suspension preparations for ID and AST card:-

\section{Suspension Preparation for ID Card}

First Transfer $3 \mathrm{ml}$ of saline into a test tube. Select an isolated colony and dissolve it.
Mix well and check the density with densicheck. Inoculum density for GPC should be between $0.5-0.63 \mathrm{MCF}$. Then place the ID card into the test tube and then transfer the test tube into the Cassette.

\section{Suspension Preparation for AST Card}

First Transfer $3 \mathrm{ml}$ of saline into a Test Tube. Transfer 280 microlitre of the ID suspension into the saline test tube. Then place the AST card into the test tube and then transfer the test tube into the cassette.

Step 2: Filling and Loading the card into VITEK 2 System:

Set all the Test Tubes containing Cards and suspension a Cassette. From PC work station print Cassette worksheet and record job ID and bar code for each card. When instrument status is $\mathrm{OK}$, then press start fill button. Remove the Cassette from the loading station when the machine indicates.

Step 3: Entering Specimen information:

Log in to window and then into VITEK2software with username and password. In the main view, click on the cassetteicon. Find the Cassette that has been loaded in the navigation tree on the left side and enter job ID from work sheet and organism name for isolates on with AST cards only. Use define isolates button to link ID and AST cards of the same specimen. Then click the save button.

Step 4: Entering patient information:

In patient icon, click new patient icon. Enter patient and Specimen information and then save. Then see the result on click icon on the main view.

\section{Antibiotics used}

The antibiotics used in this investigation were: Quinupristin/Dalfopristin, Cefoxitin 
Screen, Benzylpenicillin, Oxacillin, Gentamicin High Level, Gentamicin, Ciprofloxacin, Levofloxacin, Inducible Clindamycin Resistance, Erythromycin, Clindamycin, Daptomycin, Vancomycin, Tetracycline, Tigecycline, Nitrofurantoin, Rifampicin, Trimethoprim/Sulfamethoxaole, Linezolid, Moxifloxacin, Amikacin, and Teicoplanin. The control strains were run simultaneously with the test organisms.

\section{Quality Control}

The quality control strains Enterococcus casseliflavus ATCC 700327, S. aureus ATCC 29213 were included for identification; S. aureus ATCC 29213 and Enterococcus faecalis ATCC 29212 were included for AST.

\section{Statistical Analysis}

Results obtained were analyzed by counts and percentages using Statistical methods.

\section{Results and Discussion}

Out of 70 various pyogenic samples received in the Microbiology Lab from various departments of associated group of hospitals, Dr. S. N. Medical College for aerobic culture and sensitivity by Vitek-2, $42(60 \%)$ were male patients and $28(40 \%)$ were female patients giving a male : female ratio of $3: 2$ (Figure 1). The most predominant Gram positive bacteria isolated was Staphylococcus aureus (40\%), followed by Enterococcus (37.14\%) and CONS $(22.85 \%)$ shown in [Table 1]. [Table 2] shows sample wise distribution of various gram positive cocci. Graphical representation of percentage of Staphylococcus aureus, Enterococcus and CONS in various pyogenic samples is shown in [Figure 2, 3 \& 4] respectively. Percentage distribution of various clinical samples is shown in [Table 3].

The Antibiogram of gram positive cocci [Table 4,5 \& 6] obtained by Vitek-2 revealed that Tigecycline $(58.33 \%)$ was the most susceptible drug followed by Nitrofurantoin $(45.69 \%)$ and Vancomycin (40.36\%). Staphylococcus aureus was most susceptible to Nitrofurantoin $(57.14 \%)$ followed by Tigecycline $(50.00 \%)$ and Linezolid (39.28\%). MRSA was detected with the help of Cefoxitin screen and 16 (57.14\%) were found to be MRSA. Enterococcus was most susceptible [Table $3]$ to Vancomycin $(57.69 \%)$ followed by Linezolid (53.84 \%) and Tigecycline (50\%). CONS was most susceptible [Table 4] to Tigecycline $(75.00 \%)$ followed by Nitrofurantoin $(50.00 \%)$.

Infectious diseases are the highest reported ailments encountered in many developing countries. They are the world's major threat to human health. Rapid development of multidrug resistance by the microorganisms to available antimicrobial agents has further complicated the threat of infectious diseases to human health, for that we require a periodic monitoring of clinical samples so that appropriate choice of drug can limit such infections which appear to be great threat to physicians in patient care ${ }^{(25)}$.

In our study the data revealed that the incidence of growth was highest in tracheal secretion $25(38.25 \%)$ followed by Pus 12 $(18.12 \%)$, Sputum $11(14.97 \%)$ and Urine $17(22.50 \%)$ which is notin accordance with study of Qureshiet. al. ${ }^{(26)}$ and Zafar et.al. ${ }^{(27)}$ as in their study the incidence of growth was higher in Pus samples (213). 


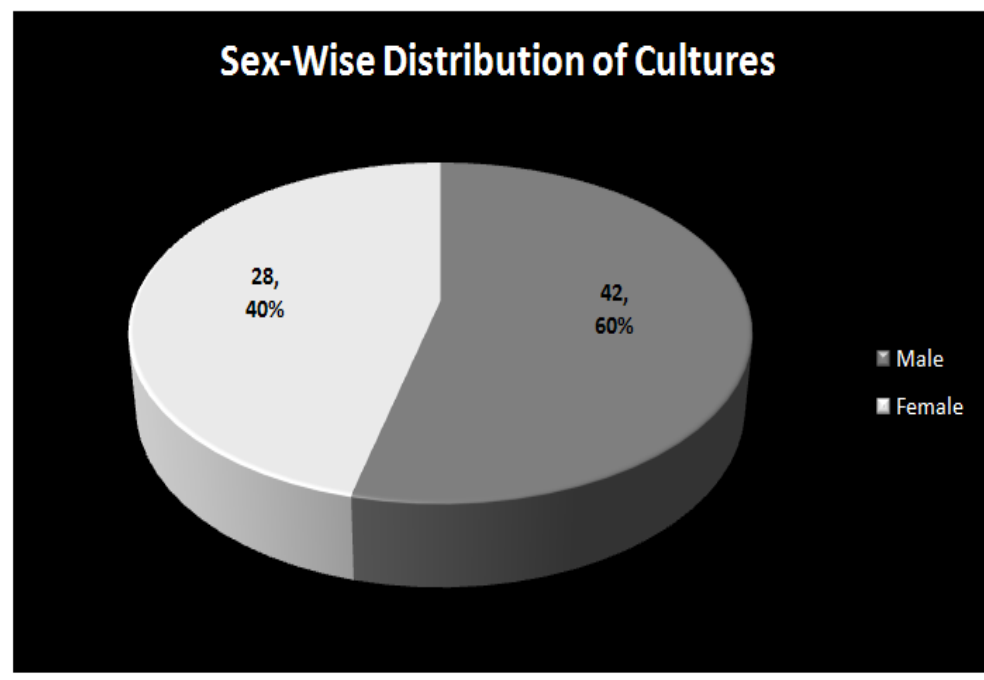

Figure.1 Pie-chart showing sex-wise distribution of cultures obtained from various clinical specimens along with percentage

Table.1 Various Bacterial Isolates and their Frequency

\begin{tabular}{|r|l|c|c|}
\hline $\begin{array}{r}\text { S. } \\
\text { No. }\end{array}$ & \multicolumn{1}{|c|}{ Name of the bacteria } & Total no. of Bacteria & Percentage \\
\hline 1. & Staphylococcus aureus & 28 & $40.00 \%$ \\
\hline 2. & Enterococcus species & 26 & $37.14 \%$ \\
\hline 3. & $\begin{array}{l}\text { Coagulase negative } \\
\text { Staphylococcus }\end{array}$ & 16 & $22.85 \%$ \\
\hline
\end{tabular}

Table.2 Frequency of Various Bacterial Isolates in Various Pyogenic Samples

\begin{tabular}{|c|c|c|c|c|}
\hline S. No. & $\begin{array}{l}\text { Name of the gram positive } \\
\text { Bacteria }\end{array}$ & Sample Type & $\begin{array}{l}\text { No. of the gram } \\
\text { positive Bacteria }\end{array}$ & $\begin{array}{l}\text { Total no. of the Gram } \\
\text { positive Bacteria }\end{array}$ \\
\hline \multirow[t]{7}{*}{1.} & \multirow[t]{7}{*}{ Staphylococcus aureus } & Pus & 05 & \multirow{7}{*}{28} \\
\hline & & Sputum & 08 & \\
\hline & & Tracheal Secretion & 11 & \\
\hline & & Urine & 01 & \\
\hline & & Vaginal Swab & 01 & \\
\hline & & Pericardial Fluid & 01 & \\
\hline & & Central Line Tip & 01 & \\
\hline \multirow[t]{5}{*}{2.} & \multirow[t]{5}{*}{ Enterococcus species } & Pus & 03 & \multirow{5}{*}{26} \\
\hline & & Sputum & 01 & \\
\hline & & Tracheal Secretion & 05 & \\
\hline & & Urine & 15 & \\
\hline & & Peritoneal Fluid & 02 & \\
\hline \multirow[t]{4}{*}{3.} & \multirow{4}{*}{$\begin{array}{l}\text { Coagulase Negative } \\
\text { Staphylococcus }\end{array}$} & Pus & 04 & \multirow{4}{*}{16} \\
\hline & & Sputum & 02 & \\
\hline & & Tracheal Secretion & 09 & \\
\hline & & Urine & 01 & \\
\hline & \multicolumn{3}{|l|}{ Total } & 70 \\
\hline
\end{tabular}


Table.3 Percentage Distribution of Various Clinical Specimens

\begin{tabular}{|c|l|c|}
\hline S No. & Sample Type & Percentage \\
\hline 1. & Pus & $18.12 \%$ \\
\hline 2. & Sputum & $14.97 \%$ \\
\hline 3. & Urine & $22.50 \%$ \\
\hline 4. & Tracheal secretion & $38.25 \%$ \\
\hline 5. & Vaginal swab & $03.57 \%$ \\
\hline 6. & Pericardial fluid & $03.57 \%$ \\
\hline 7. & Central line tip & $03.57 \%$ \\
\hline 8. & Peritoneal Fluid & $07.69 \%$ \\
\hline
\end{tabular}

Table.4 Antibiotic Susceptibility Pattern of Staphylococcus aureus $(n)=28$

\begin{tabular}{|l|c|c|l|c|c|}
\hline \multicolumn{1}{|c|}{ Antibiotics } & \multicolumn{2}{c|}{ Sensitive } & \multicolumn{2}{c|}{ Antibiotics } & \multicolumn{2}{c|}{ Sensitive } \\
\hline & Number & Percentage & & Number & Percentage \\
\hline Quinupristin/Dalfopristin & 04 & 14.28 & Daptomycin & 07 & 25.00 \\
\hline Cefoxitin Screen & 16 & 57.14 & Vancomycin & 09 & 32.14 \\
\hline Benzylpenicillin & 04 & 14.28 & Tetracycline & 08 & 28.57 \\
\hline Oxacillin & 05 & 17.85 & Tigecycline & 14 & 50.00 \\
\hline Gentamicin High Level & 04 & 14.28 & Nitrofurantoin & 16 & 57.14 \\
\hline Gentamicin & 08 & 28.57 & Rifampicin & 09 & 32.14 \\
\hline Ciprofloxacin & 03 & 10.71 & Cotrimoxazole & 10 & 35.71 \\
\hline Levofloxacin & 08 & 28.57 & Linezolid & 11 & 39.28 \\
\hline $\begin{array}{l}\text { Inducible Clindamycin } \\
\text { Resistance }\end{array}$ & 05 & 17.85 & Moxifloxacin & 03 & 10.71 \\
\hline Erythromycin & 03 & 10.71 & Amikacin & 01 & 03.57 \\
\hline Clindamycin & 02 & 07.14 & Teicoplanin & 06 & 21.42 \\
\hline
\end{tabular}

Table.5 Antibiotic Susceptibility Pattern of Enterococcus spp. (n) = 26

\begin{tabular}{|l|c|c|l|c|c|}
\hline \multicolumn{1}{|c|}{ Antibiotics } & \multicolumn{2}{c|}{ Sensitive } & \multicolumn{2}{c|}{ Antibiotics } & \multicolumn{2}{c|}{ Sensitive } \\
\hline & Number & Percentage & & Number & Percentage \\
\hline Quinupristin/Dalfopristin & 06 & 23.07 & Daptomycin & 01 & 3.84 \\
\hline Cefoxitin Screen & - & - & Vancomycin & 15 & 57.69 \\
\hline Benzylpenicillin & - & - & Tetracycline & 06 & 23.07 \\
\hline Oxacillin & - & - & Tigecycline & 13 & 50.00 \\
\hline Gentamicin High Level & 02 & 7.69 & Nitrofurantoin & 08 & 30.76 \\
\hline Gentamicin & - & - & Rifampicin & - & - \\
\hline Ciprofloxacin & 01 & 3.84 & Cotrimoxazole & 04 & 15.38 \\
\hline Levofloxacin & 02 & 7.69 & Linezolid & 14 & 53.84 \\
\hline $\begin{array}{l}\text { Inducible Clindamycin } \\
\text { Resistance }\end{array}$ & - & - & Moxifloxacin & 01 & 3.84 \\
\hline Erythromycin & - & - & Amikacin & & - \\
\hline Clindamycin & - & - & Teicoplanin & 02 & 7.69 \\
\hline
\end{tabular}


Table.6 Antibiotic Susceptibility Pattern of Coagulase Negative Staphylococcus (n) $=16$

\begin{tabular}{|l|c|c|l|c|c|}
\hline \multicolumn{1}{|c|}{ Antibiotics } & \multicolumn{2}{c|}{ Sensitive } & \multicolumn{2}{c|}{ Antibiotics } & \multicolumn{2}{c|}{ Sensitive } \\
\hline Quinupristin/Dalfopristin & Number & Percentage & & Number & Percentage \\
\hline Cefoxitin Screen & 07 & 06.25 & Daptomycin & - & - \\
\hline Benzylpenicillin & - & 43.75 & Vancomycin & 05 & 31.25 \\
\hline Oxacillin & 01 & 06.25 & Tetracycline & 02 & 12.50 \\
\hline Gentamicin High Level & - & - & Nitrofurantoin & 08 & 75.00 \\
\hline Gentamicin & 02 & 12.50 & Rifampicin & 02 & 50.00 \\
\hline Ciprofloxacin & 02 & 12.50 & Cotrimoxazole & 04 & 25.00 \\
\hline Levofloxacin & 03 & 18.75 & Linezolid & 03 & 18.75 \\
\hline $\begin{array}{l}\text { Inducible Clindamycin } \\
\text { Resistance }\end{array}$ & - & - & Moxifloxacin & 04 & 25.00 \\
\hline Erythromycin & 03 & 18.75 & Amikacin & - & - \\
\hline Clindamycin & 02 & 12.50 & Teicoplanin & 01 & 06.25 \\
\hline
\end{tabular}

Figure.2 Graphical Representation of Staphylococcus aureus Obtained from Various Pyogenic Samples

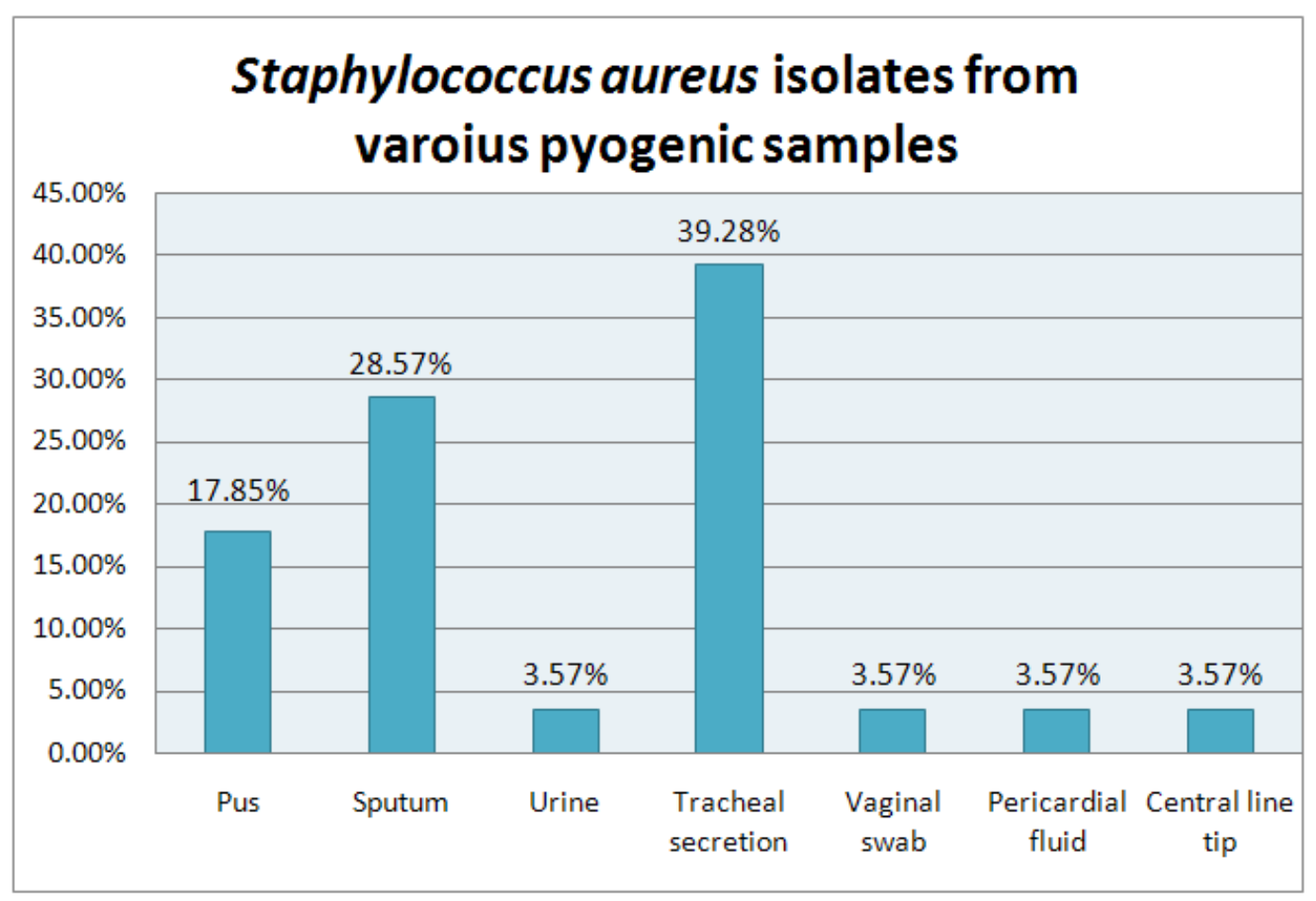


Figure.3 Graphical Representation of Enterococcus Obtained from Various Pyogenic Samples

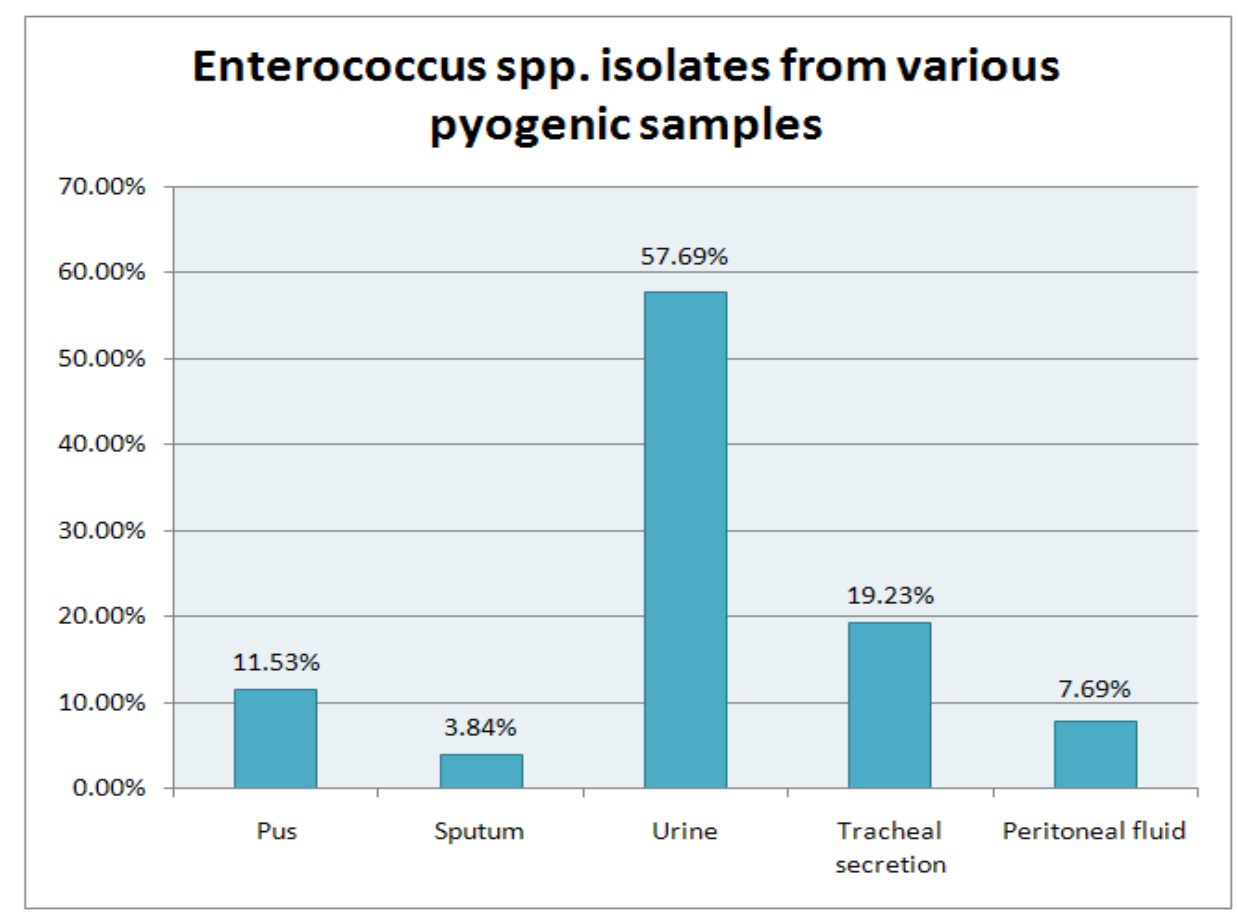

Figure.4 Graphical Representation of Staphylococcus Species Coagulase Negative Obtained from Various Pyogenic Samples

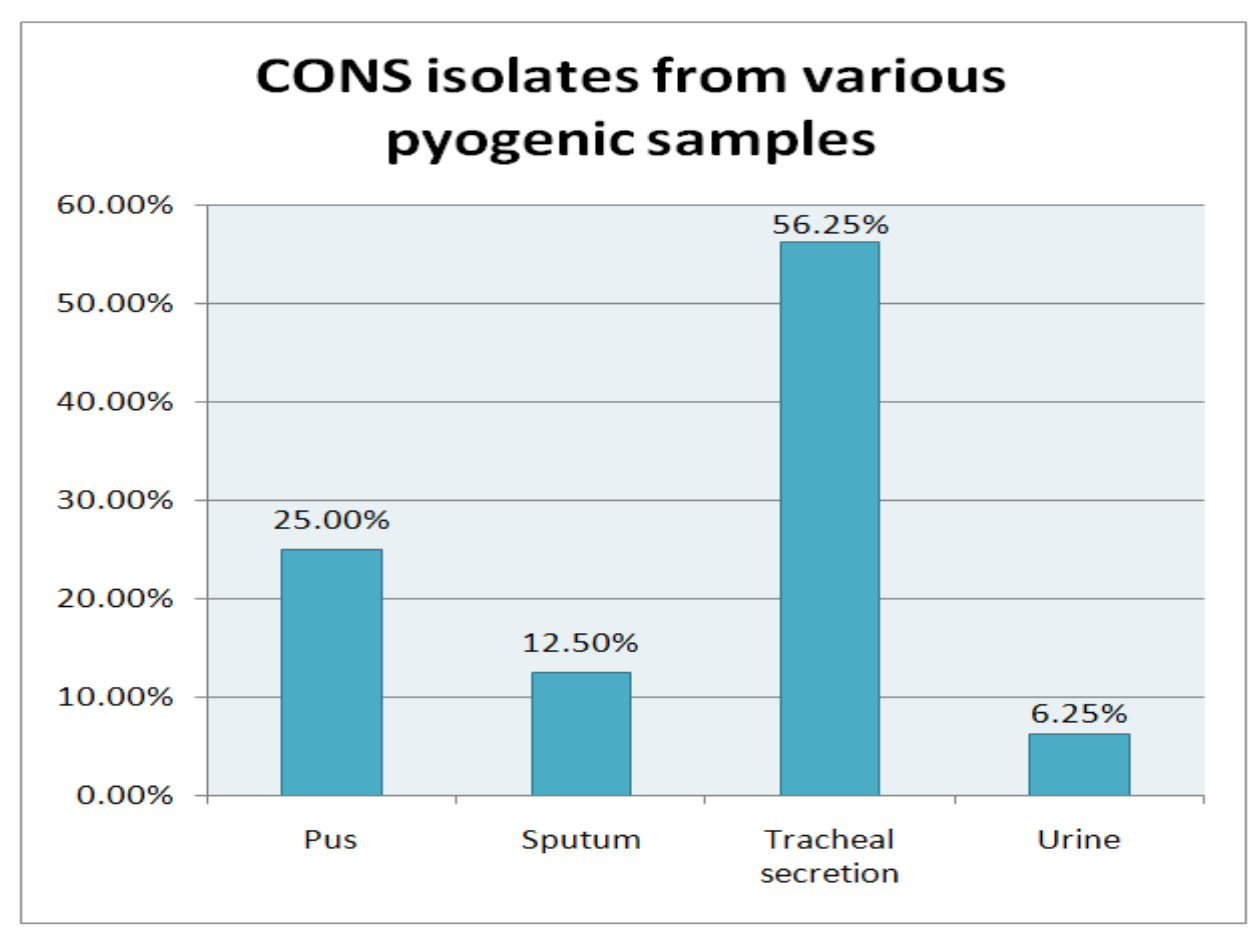


Gender based observation of 70 isolates showed higher frequency among Male patients $60 \%$, than in Female patients $40 \%$ (Fig.1). Male to female ratio was 3:2 which is in consistence with earlier work byPappu et al.,2011 $(1.43: 1)^{(28)}$,ZinnatShahina et al $(1: 0.6)^{(29)}$,Mahmood et.al. ${ }^{(30)}$ and L D Kitara et.al. $^{(31)}$, but disagrees with the findings of Idighri et.al. ${ }^{(32)}$, that females $(32 \%)$ were higher in ratio than the males(30\%).

Majority of our results are monomicrobial and $S$. aureus was found to be the most common pathogen in our study $(40.00 \%)$. Similar report was also observed by Basu $\mathrm{S}$ et al.,2009 ${ }^{(33)}$; Lee CY et al., 2009 ${ }^{(34)}$; Tiwari, etal., 2010 ${ }^{(35)}$. Agnithori $\mathrm{N}$ et $\mathrm{al}^{(36)}$ found it to be second most common isolate .Among S. aureus $57.14 \%$ wasfound to be MRSA (Cefoxitin resistant). Anupurba et al., $\quad(2003)^{(37)}$ observed $32 \%$ and Rajaduraipandi et al., (2006) ${ }^{(38)}$ observed $31 \%$ of MRSA in their study.

Antibiogram of gram positive cocci revealed that they show highest susceptibility towards Tigecycline (58.33\%), followed by Nitrofurantoin (45.69\%), Vancomycin (40.36\%), and Linezolid (37.29\%) which is in contrast to the study of G Suguneswari et al (39) which reveals $100 \%$ sensitivity to Vancomycin, $76.92 \%$ to Levofloxacin, \& $73.07 \%$ to Oxacillin.

Our study reveals that Staphylococcus aureus was most susceptible to Nitrofurantoin (57.14\%) followed by Tigecycline $(50.00 \%)$ and Linezolid (39.28\%) contrary to $100 \%$ sensitivity to Vancomycin and Linezolidin the study of Samra et $\mathrm{al}^{(40)}$.

This assertion can further be strengthened by the high level of antibiotic abuse in our locality, arising from self medication which are often associated with inadequate dosage and failure to comply to treatment ${ }^{(41)}$ and availability of antibiotics to consumers across the counters with or without prescription ${ }^{(42,43)}$.As antibiotic resistance grow day by day, it is important to use suitable antibiotic after proper laboratory diagnosis such as culture and antibiotic susceptibility tests and treatment should be depend on it $^{(29)}$.

In conclusion, Pyogenic infection has been the major cause of mortality and morbidity since long. Emerging of multidrug resistant strains is of major concern to treat these conditions. Even though gram negative bacteria are being increased significantly but still Staphylococcus aureus is being continued as a major etiological agent of pyogenic infections. Changing antimicrobial resistance pattern poses challenge in treating these conditions. Appropriate and judicious selection of antibiotics by using antibiotic sensitivity data and also by avoiding overuse, frequent misuse, inadequate dosages, easy availability of antimicrobials would limit the emerging drug resistant strains in the future to treat these clinical conditions successfully. A changing trend in the antibiotic sensitivity profile of the isolates needs to be monitored as there is limited availability of newer drugs and the emergence of resistant bacteria far exceeds the rate of new drug development. Our study thereby will guide the clinician in choosing appropriate antibiotics which not only contributes to better treatment but their judicious use will also help in preventing emergence of resistance to the drugs which are still sensitive and also, compared to the standard methods used, the use of Vitek-2 compact system would reduce the turnaround time by at least $16 \mathrm{hrs}$ which will also be very useful for the clinician.

\section{References}

1. Koneman, W.K., Allen, S. D., Janda, W.M., Schreckenberger, P.C., Propcop, 
G.W., Woods, G.L. and Winn, W.C., Jr. Philadelphia Color Atlas and Textbook of Diagnostic Microbiology, 6th ed. Lippincott-Raven Publisher, 2005, pp: 624-662.

2. D.V.M.V.S.V. RaghavRao,RanjanBasu, Debika Roy Biswas, Dept. of Microbiology, GSL Medical College, Rajahmundry, Andhra Pradesh. IOSR Journal of Dental and Medical Sciences (IOSR-JDMS) e-ISSN: 2279-0853, pISSN: 2279-0861. Volume 13, Issue 3 Ver. II. (Mar. 2014), PP 59-62 www.iosrjournals.org www.

3. Motce, K. and Liamthorg, S. (2007).Food borne. Pathog Dis., 2: 115116.

4. K. Radha, R. Uma, G. Ramanathan and V. Thangapandian J. Microbiol. Biotech. Res., 2012, 2 (1):138-146

5. Cownely L.E. (2008).Nat.rev. microbial. 6(3): 187-89.

6. Waldor MK. Disarming pathogens-a new approach for antibiotic development. N. Engl. J. Med. 2006; 354: 296-297.

7. Alanis AJ. Resistance to antibiotics: are we in the post-antibiotic era? Arch. Med. Res. 2005; 36: 697-705.

8. Bax R, Mullan N, Verhoef J. The millennium bugs-the need for and development of new antibacterials. Int. J. Antimicrob. Agents. 2000;16: 51-59.

9. Norrby SR, Nord CE, Finch R. Lack of development of new antimicrobial drugs: a potential serious threat to public health. Lancet Infect. Dis. 2005;5: 115-119.

10.Ojulong J, Mwambu TP, Jalooba M, Bwanga F, Kaddu-Mulindwa DH. Relative prevalence MethicillinResistant Staphylococcus aureus and its susceptibility pattern in Mulago Hospital, Kampala, Uganda. Tanzania $J$ Health Research. 2009;11(3):149-153.
11.Cornaglia, G., G. Lo Cascio, L. Masala, The Italian Surveillance Group for Antimicrobial Resistance, and R. Fontana. 2000. Macrolide resistance among $S$. pneumoniae isolates in Italy, $\mathrm{p}$. 250-254.In S. H. Zinner, L. S. Young, J. F. Acar, and C. Ortiz-Neu (ed.), New considerations for macrolides, azalides, streptogramins, and ketolides. M. Dekker, Inc., New York, N.Y.

12.Fontana, R., M. Ligozzi, A. Mazzariol, G. Veneri, The Italian SurveillanceGroup for Antimicrobial Resistance, and G. Cornaglia. 1998. Resistance of enterococci to ampicillin and glycopeptide antibiotics in Italy. Clin. Infect. Dis. 27:8486. [PubMed]

13.Fontana, R. 1985. Leading article: penicillin-binding proteins and the intrinsic resistance to beta-lactams in Gram-positive cocci. J. Antimicrob. Chemother. 16:412-416. [PubMed]

14. Murray, B. E. 1990. The life and times of the enterococcus. Clin. Microbiol. Rev. 3:46-65.

15.Pfaller, M. A., and L. A. Herwaldt. 1988. Laboratory, clinical, and epidemiological aspects of coagulase-negative staphylococci. Clin. Microbiol. Rev. 1: 281-299.

16. Woodford, N., A. P. Johnson, D. Morrison, and D. C. E. Speller. 1995. Current perspective on glycopeptide resistance. Clin. Microbiol. Rev. 8:585615.

17. Marco Ligozzi, Cinzia Bernini, Maria Grazia Bonora, Maria de Fatima, Jessica Zuliani, and Roberta FontanaJ Clin Microbiol. 2002 May; 40(5): 16811686.doi: 10.1128/JCM.40.5.16811686.2002.

18.Barenfanger J, Drake C, Kacich G. Clinical and financial benefits of rapid bacterial identification and antimicrobial 
susceptibility testing. J Clin Microbiol. 1999;37:1415-8.

19. Barenfanger J, Short MA, Groesch AA. Improved antimicrobial interventions have benefits. $\mathrm{J}$ Clin Microbiol. 2001;39:2823-8.

20.Chorny JA, Wilson ML. Rapid detection and identification of microorganisms from blood cultures. Clin Lab Med. 1994;14:181-95.

21.Doern GV, Vautour R, Gaudet M, Levy B. Clinical impact of rapid in vitro susceptibility testing and bacterial identification. J Clin Microbiol. 1994; 32:1757-62.

22.Trenholme GM, Kaplan RL, Karakusis PH, Stine T, Fuhrer J, Landau W, et al. Clinical impact of rapid identification and susceptibility testing of bacterial blood culture isolates. J Clin Microbiol. 1989;27:1342-5.

23.Funke, G., Monnet, C. deBernardis, A. von Graevenitz, and J. Freney. 1998. Evaluation of the VITEK 2 system for rapid identification of medically relevant gram-negative rods. J. Clin. Microbiol.36:1948-1952.

24.http://www.micro4cosmetics.com/vitek ms-vitek2compact-api.html

25. M. Chauhan, Manish S and S. Mahajan Int.J.Curr.Microbiol.App.Sci ISSN: 2319-7706 Volume 4 Number 5 (2015) pp. 784-787.

26.Qureshi AH, Rafi S, Qureshi SM, Ali AM. The current susceptibility patterns of Methicillin resistant Staphylococcus aureus to conventional anti Staphylococcus antimicrobials at Rawalpindi. Pak J Med Sci.2004; 20: 361-364.

27. Zafar A, Ejaz H, Ahmed JM, Javed A. Frequency and Antimicrobial Susceptibility of Staphylococcus Aureus isolated from pus Samples of Paediatric patients. Pjmhsonline 2012;vol.6(3): 3235.

28.Pappu AK, Sinha A, Johnson A. Microbiological profile of Diabetic foot ulcer. Calicut Medical Journal 2011; 9(3)e 2

29. Zinnat Shahina1, A. H. M. Ishaque Chowdhury1, Md. Arifuzzaman2 IOSR Journal of Dental and Medical Sciences (IOSR-JDMS) e-ISSN: 2279-0853, pISSN: 2279-0861. Volume 13, Issue 1 Ver. IV (Jan. 2014), PP 53-57.

30.Mahmood K, Tahir T, Jameel $T$, Ziauddin A and Alam H F. Incidence of Methicillin-resistant Staphylococcus aureus (MRSA) causing nosocomial infection in a tertiary care hospital. Annals.2010;vol16(2):91-96.

31. Kitara LD, Anywar Ad, Acullu D, Odongo-Aginya E, Aloyo $\mathrm{J}$ and Fendu M. Antibiotic susceptibility of Staphylococcus aureus in suppurative lesions in Lacor Hospital, Uganda. African Health sci.2011;11(S1): S34S39.

32.Idighri M N, Nedolisa A C and Egbujo E C. Antimicrobial susceptibility pattern of Staphylococcus aureus isolated from surgical wound of patients in Jos University Teaching hospital, North central Nigeria. E- international scientific research journal. 2012;IV(1): ISSN 2094-1749.

33. Basu S, Ramchuran Panray T, Bali Singh T, Gulati AK, Shukla VK. A prospective, descriptive study to identify the microbiological profile of chronic wounds in outpatients. Ostomy Wound Manage. 2009 ; 55:14-20.

34.Lee CY, Chen PY, Huang FL, Lin CF.Microbiologic spectrum and susceptibility pattern of clinical isolates from the pediatric intensive care unit in a single medical center - 6 years' experience. J Microbiol Immunol Infect. $2009 ; 42: 160-5$. 
35.Tiwari P, Kaur S. Profile and sensitivity pattern of bacteria isolated from various cultures in a Tertiary Care Hospital in Delhi. Indian J Public Health. 2010; 54:213-5.

36. Agnihotri N, Gupta V, Joshi RM. Aerobic bacterial isolates from burn wound infections and their antibiograms - a five-year study. Burns. 2004 May; 30(3):241-3.

37.Anupurba S, Sen MR, Nath G, Sharma BM, Gulati AK, Mohapatra TM. Prevalence of methicillin resistant Staphylococcus aureus in a tertiary referral hospital in eastern Uttar Pradesh. Ind J Med. Microbiol 2003; 21:49-51.

38.Rajaduraipandi K, Mani KR, Panneerselvam K, et al. Prevalence and antimicrobial susceptibility pattern of methicillin resistant Staphylococcus aureus. A multicentric study. Ind J Med Microbiol 2006; 24:34-8.

39.G. Suguneswari, A. Heraman Singh, Ranjan Basu .bacteriological profile of osteomyelitis in a tertiary care hospital at Visakhapatnam. IJCRR; $2013 ; 05(20)$.
40.Samra Z, Ofer O, Shmuely H. Susceptibility of methicillin resistant Staphylococcus aureus to vancomycin, teicoplanin, linezolid, pristinamycin and other antibiotics. The Israel Medical Association Journal March 2005; 7(3): 148-150.

41.Ramakrishna D. Prevalence and multi drug resistance of Staphylococcus aureus in the hospitals of Gulbarga and Raichur districts. Recent research in Science and Technology. 2012;4(2): 27-29.

42. Odegbemi T. The use and abuse of antibiotics. Nig. Med. Pract. 1981;1(1):5-8.

43. Adekeye D. Resistance of Staphylococcus aureus of man and other animal to five antibiotics commonly used in Nigeria. Nig. Med. J. 1979;9: 195-197.

\section{How to cite this article:}

Shivani Khullar, Laxmi Rathore, P. K. Khatri, R. S. Parihar, Saroj Meena, Archana Bora, Vinod Maurya and Niranjan Sharma. 2016. Identification and Antibiogram of Various Gram Positive Bacterial Isolates from Pyogenic Samples by VITEK® 2 Compact System. Int.J.Curr.Microbiol.App.Sci. 5(2): 66-77. doi: http://dx.doi.org/10.20546/ijcmas.2016.502.007 